University of Wollongong

Research Online

Australian Institute for Innovative Materials -

Papers

Australian Institute for Innovative Materials

2008

Influence of inductance variation on performance of a permanent magnet claw pole soft magnetic composite motor

Youguang Guo

Hebei University of Technology

Jian Zhu

University of Technology, Sydney

Zhi Lin

University of Technology, Sydney

Haiyan Lu

University of Technology, Sydney

Xiaolin Wang

University of Wollongong, xiaolin@uow.edu.au

See next page for additional authors

Follow this and additional works at: https://ro.uow.edu.au/aiimpapers

Part of the Engineering Commons, and the Physical Sciences and Mathematics Commons

Research Online is the open access institutional repository for the University of Wollongong. For further information contact the UOW Library: research-pubs@uow.edu.au 


\title{
Influence of inductance variation on performance of a permanent magnet claw pole soft magnetic composite motor
}

\author{
Abstract \\ Winding inductance is an important parameter in determining the performance of electrical machines, \\ particularly those with large inductance variation. This paper investigates the influence of winding \\ inductance variation on the performance of a three-phase three-stack claw pole permanent magnet motor \\ with soft magnetic composite (SMC) stator by using an improved phase variable model. The winding \\ inductances of the machine are computed by using a modified incremental energy method, based on \\ three-dimensional nonlinear time-stepping magnetic field finite element analyses. The inductance \\ computation and performance simulation are verified by the experimental results of an SMC claw pole \\ motor prototype.

\section{Keywords} \\ composite, claw, magnet, motor, influence, variation, magnetic, pole, soft, permanent, performance, \\ inductance \\ Disciplines \\ Engineering | Physical Sciences and Mathematics

\section{Publication Details} \\ Guo, Y., Zhu, J. Guo., Lin, Z. Wei., Lu, H., Wang, X. \& Chen, J. (2008). Influence of inductance variation on \\ performance of a permanent magnet claw pole soft magnetic composite motor. In 2007 52nd Annual \\ Conference on Magnetism and Magnetic Materials, 5-9 November, Tampa, Florida. Journal of Applied \\ Physics, 103 (7), 07F118-1-07F118-3.
}

\section{Authors}

Youguang Guo, Jian Zhu, Zhi Lin, Haiyan Lu, Xiaolin Wang, and Jiaxin Chen 


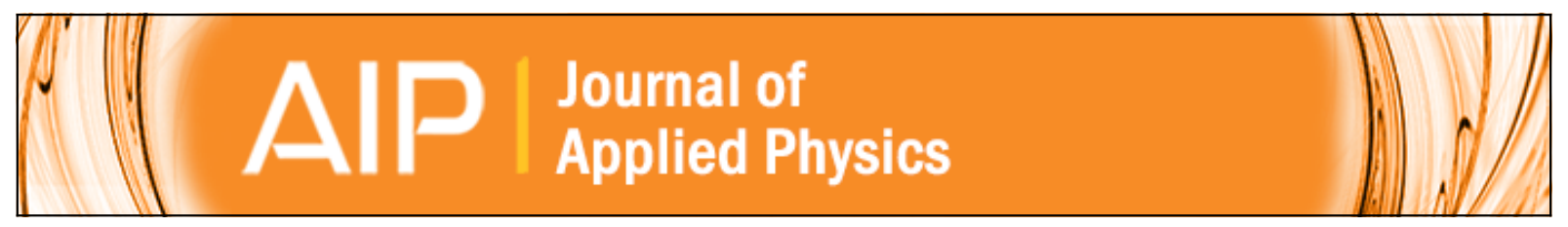

\section{Influence of inductance variation on performance of a permanent magnet claw pole soft magnetic composite motor}

Youguang Guo, Jian Guo Zhu, Zhi Wei Lin, Haiyan Lu, Xiaolin Wang, and Jiaxin Chen

Citation: Journal of Applied Physics 103, 07F118 (2008); doi: 10.1063/1.2834397

View online: $\mathrm{http}: / / \mathrm{dx}$.doi.org/10.1063/1.2834397

View Table of Contents: http://scitation.aip.org/content/aip/journal/jap/103/7?ver=pdfcov

Published by the AIP Publishing

\section{Articles you may be interested in}

Comparison of electromagnetic performance of brushless motors having magnets in stator and rotor J. Appl. Phys. 103, 07F124 (2008); 10.1063/1.2838222

Slanted and saw-toothed stator poles for improved performance of doubly salient permanent magnet motor J. Appl. Phys. 97, 10Q514 (2005); 10.1063/1.1860831

Practical parameter estimation through space harmonic method and experiment of permanent magnet linear synchronous motor for high accuracy field orient control

J. Appl. Phys. 97, 10N517 (2005); 10.1063/1.1855275

Armature reaction field and inductances of tubular modular permanent magnet machines J. Appl. Phys. 97, 10Q504 (2005); 10.1063/1.1852324

Study of internal permanent magnet rotor made of $0.6 \mathrm{C}-13 \mathrm{Cr}-\mathrm{Fe}$ dual state magnetic material J. Appl. Phys. 93, 8769 (2003); 10.1063/1.1556983

\section{A|P| Journal of}

Journal of Applied Physics is pleased to announce André Anders as its new Editor-in-Chief 


\title{
Influence of inductance variation on performance of a permanent magnet claw pole soft magnetic composite motor
}

\author{
Youguang Guo, ${ }^{1, a)}$ Jian Guo Zhu, ${ }^{2}$ Zhi Wei Lin, ${ }^{2}$ Haiyan $L u,{ }^{2}$ Xiaolin Wang, ${ }^{3}$ and \\ Jiaxin Chen ${ }^{4}$ \\ ${ }^{1}$ Province-Ministry Joint Key Laboratory of Electromagnetic Field and Electrical Apparatus Reliability, \\ Hebei University of Technology, Tianjin, 300130, China \\ ${ }^{2}$ Faculty of Engineering and Information Technology, University of Technology, Sydney, New South Wales \\ 2007, Australia \\ ${ }^{3}$ Institute for Superconducting and Electronic Materials, University of Wollongong, \\ New South Wales 2522, Australia \\ ${ }^{4}$ College of Electromechanical Engineering, Donghua University, Shanghai, 200051, \\ People's Republic of China
}

(Presented on 8 November 2007; received 13 September 2007; accepted 29 October 2007; published online 10 March 2008)

\begin{abstract}
Winding inductance is an important parameter in determining the performance of electrical machines, particularly those with large inductance variation. This paper investigates the influence of winding inductance variation on the performance of a three-phase three-stack claw pole permanent magnet motor with soft magnetic composite (SMC) stator by using an improved phase variable model. The winding inductances of the machine are computed by using a modified incremental energy method, based on three-dimensional nonlinear time-stepping magnetic field finite element analyses. The inductance computation and performance simulation are verified by the experimental results of an SMC claw pole motor prototype. (C) 2008 American Institute of Physics.
\end{abstract}

[DOI: $10.1063 / 1.2834397$ ]

\section{INTRODUCTION}

Soft magnetic composite (SMC) materials and their application in electrical machines have achieved significant development in the past decade, thanks to the materials' unique properties such as magnetic isotropy, very low eddy current loss, and relatively low total core loss at medium and higher frequencies, and prospect of very low cost net-shape fabrication by using the well-developed powder metallurgical molding techniques. ${ }^{1}$ The major advantage may be with the isotropic magnetic property, which provides great benefits to electrical machine design. The constraints imposed by the conventional laminated steel, such as that the flux must flow within the lamination plane, can now be ignored, so that electrical machines with radically different topologies can be exploited to acquire the best performance. ${ }^{2}$ Typical examples of SMC application include claw pole and transverse flux motors, in which the magnetic field is really threedimensional (3D). ${ }^{3}$ In such machines, it is very difficult or almost impossible to construct the core by using the laminated steel because the magnetic flux has significant component in any direction and the flux component perpendicular to the lamination plane may cause excessive eddy current loss. SMC offers an ideal solution to these machines.

To investigate the application potential of SMC in electrical machines, the authors of this paper have designed, fabricated, and tested several SMC motor prototypes, including a three-phase three-stack claw pole motor with SMC stator core. ${ }^{4,5}$ The motor employs an interior stator made by SMC and an exterior rotor with $20 \mathrm{NdFeB}$ permanent magnets

${ }^{a)}$ Electronic mail: youguang@eng.uts.edu.au.
(PMs) per phase on the inner surface of the mild steel rotor yoke. Three phases of the motor are stacked axially on the stator shaft with an angular shift of $120^{\circ}$ electrical to each other. Each phase has a single concentrated winding around a SMC core, which is molded in two halves. The major dimensions are $80 \mathrm{~mm}$ for the stator outer diameter, $93 \mathrm{~mm}$ for the stator effective axial length, and $1 \mathrm{~mm}$ for the main air gap. The prototype has operated successfully with a sensorless brushless dc (BLDC) scheme, delivering an output power of $500 \mathrm{~W}$ at $1800 \mathrm{rpm}$ when the stator current is $4.1 \mathrm{~A}^{5}$

Based on nonlinear time-stepping magnetic field finite element analysis (FEA), the authors have previously studied the accurate computation of key motor parameters at various loads, considering the nonlinearity of magnetic materials and effects of armature reaction. ${ }^{6-8}$ In such a machine with 3D flux structure and single concentrated winding, the inductance value and the inductance variation are generally large. This paper investigates the influence of the winding inductance, particularly its variation with respect to rotor position, on the performance of the claw pole motor.

\section{INDUCTANCE COMPUTATION}

The self-inductance of one phase winding is computed at various rotor positions by using a modified incremental energy method, ${ }^{6}$ which consists of the following steps: (1) A nonlinear FEA is conducted with the excitations of PMs (assuming the magnetic field of PMs is dominant). (2) Both the apparent and incremental permeabilities of each element are stored, which correspond to $B / H$ (flux density/field strength) and $\Delta B / \Delta H$ at the operating point $(B, H)$ of the nonlinear magnetization curve, respectively. (3) The coercive force of 


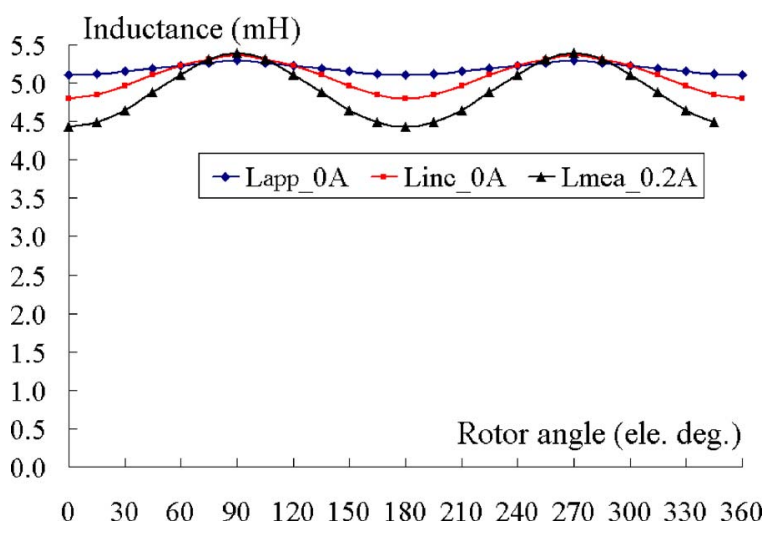

FIG. 1. (Color online) Computed and measured phase inductance.

$\mathrm{PM}$ is set as zero and a linear FEA is conducted with a perturbation current $i$ to find out the variation of magnetic coenergy $\Delta W_{f}^{\prime}$. (4) The winding inductance can then be computed by

$$
L=2 \Delta W_{f}^{\prime} / i^{2} .
$$

It should be noted that the stored apparent permeability is used for apparent inductance computation and the incremental permeability for incremental inductance. Figure 1 illustrates the computed apparent and incremental phase inductances without the effect of armature reaction. The apparent inductance is generally larger than its incremental counterpart. This agrees with the fact that apparent inductance corresponds to the slope of the secant line between the origin and the operating point of $B-H$ curve, and incremental inductance corresponds to the slope of the tangential line at the operating point.

For verification, the measured inductances are also plotted in the figure, which are obtained by using the common $V$-I method with a small ac current $(500 \mathrm{~Hz}, 0.2 \mathrm{~A})$. The error may be due to the eddy current caused by the measuring current.

The magnetic circuits of three phases are almost independent to each other, so the mutual inductance between phase windings can be considered as zero.

\section{MOTOR PERFORMANCE ANALYSIS}

The characteristic of the electrical circuit of one phase winding is governed by the voltage equation written as

$$
v_{j}=r_{j} i_{j}+d \lambda_{j} / d t+e_{j} \quad(j=a, b, c),
$$

where $v, r, i, \lambda$, and $e$ are the phase voltage, resistance, current, flux linkage, and back electromotive force (emf), respectively. The flux linkage can be written in terms of apparent inductance as

$$
\lambda_{j}=\sum_{k=a}^{c} L_{j k} i_{k} .
$$

Because the flux linkage is a function of stator currents and rotor position, the second term of Eq. (2) can be expanded as

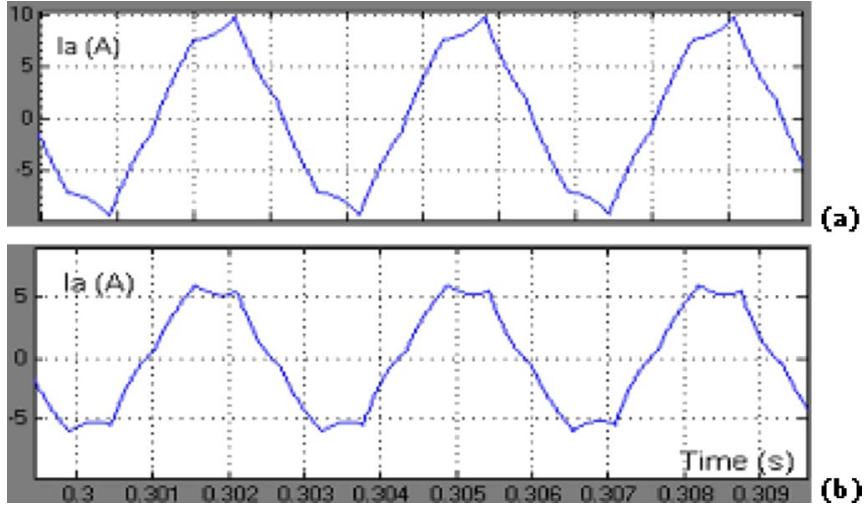

FIG. 2. (Color online) Current of a phase winding at steady state: (a) considering the effect of inductance variation and (b) with constant inductance.

$$
\frac{d \lambda_{j}}{d t}=\sum_{k=a}^{c} \frac{\partial \lambda_{j}}{\partial i_{k}} \frac{d i_{k}}{d t}+\frac{\partial \lambda_{j}}{\partial \theta_{r}} \frac{d \theta_{r}}{d t}=\sum_{k=a}^{c}\left(L_{j k}^{\prime} \frac{d i_{k}}{d t}+\frac{d L_{j k}}{d \theta_{r}} i_{k} \omega_{r}\right),
$$

where $L_{j k}$ is the apparent inductance, $L_{j k}^{\prime}$ the incremental inductance, $\theta_{r}$ the rotor mechanical angle, and $\omega_{r}$ the rotor angular speed in mechanical $\mathrm{rad} / \mathrm{s}$.

Substituting Eq. (4) into Eq. (2), the voltage equation of the $j$ th phase winding becomes

$$
v_{j}=r_{j} i_{j}+\sum_{k=a}^{c}\left(L_{j k}^{\prime} \frac{d i_{k}}{d t}+\frac{d L_{j k}}{d \theta_{r}} i_{k} \omega_{r}\right)+e_{j}
$$

The electromagnetic torque (under optimum BLDC control) and motion equation are

$$
\begin{aligned}
& T_{\mathrm{em}}=\left(\sum_{j=a}^{c} e_{j} i_{j}\right) / \omega_{r}+T_{\mathrm{cog}}, \\
& J \frac{d \omega_{r}}{d t}=T_{\mathrm{em}}-\frac{P_{\mathrm{Fe}}}{\omega_{r}}-T_{L}-\delta \omega_{r}, \quad \frac{d \theta_{r}}{d t}=\omega_{r},
\end{aligned}
$$

where $T_{\operatorname{cog}}$ is the cogging torque, $J$ the total inertia of rotating parts, $P_{\mathrm{Fe}}$ the core loss, $T_{L}$ the load torque, and $\delta$ the friction coefficient.

From Eqs. (2)-(7), it can be seen that both the apparent and incremental inductances and their variations affect the stator current and hence the electromagnetic torque and mechanical characteristics. To include this effect in the motor performance prediction, the phase variable model can be employed. $^{9}$

For the symmetrical three-phase windings, which are star-connected without central line, one has

$$
r_{j}=r_{k}, \quad L_{j k}=L_{k j}, \quad \sum_{j=a}^{c} i_{j}=0 \quad(j, k=a, b, c) .
$$

The above equations [Eqs. (2)-(8)] constitute the so-called phase variable model. The profiles of the inductances as well as the back emf, core loss, and cogging torque are obtained in advance by nonlinear time-stepping FEAs, in which magnetic saturation and rotor position dependence are considered. All the data are stored in lookup tables and will be retrieved during the motor performance simulation. 

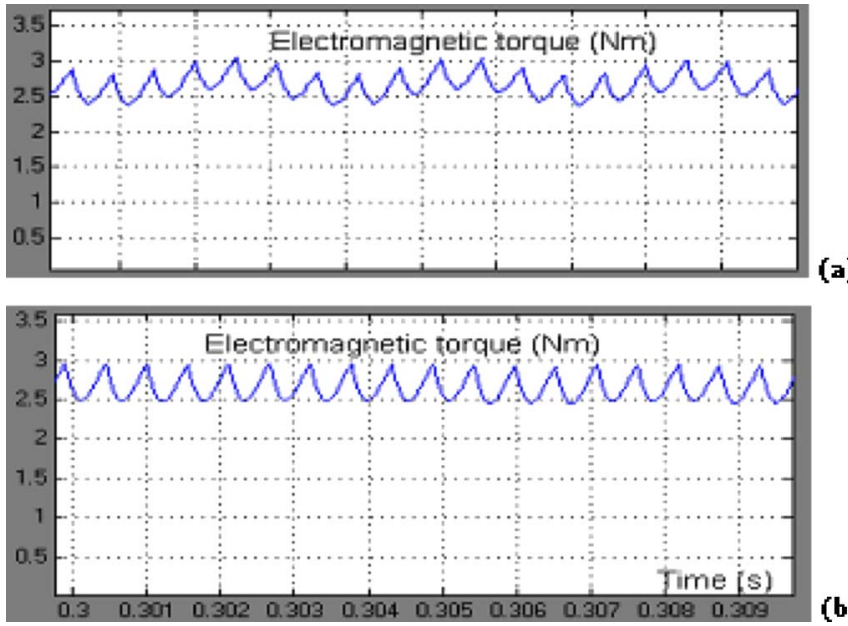

(b)

FIG. 3. (Color online) Electromagnetic torque at steady state: (a) considering the effect of inductance variation and (b) with constant inductance.

In a PM motor with BLDC control scheme, there always exists a phase winding which is open-circuited and the input voltage of the phase is immeasurable, so the equation-based model cannot be applied directly and an alternative model, composed of several circuit components, had to be used. ${ }^{9}$ Based on a pure mathematical approach, the authors of this paper developed an improved phase variable model in which the voltage of the central point of Y-connected three-phase windings is mathematically obtained and hence the equationbased simulation model can be directly applied to BLDC motors. ${ }^{10}$

According to Eqs. (2)-(8) and the mathematical approach for determining the voltage of the central point of three-phase windings, a Simulink-based simulation model is built.

By using the model, various motor performances can be predicted. For example, Fig. 2 illustrates the phase current at steady state when the inverter voltage is $165 \mathrm{~V}$ dc and the load torque is $2.65 \mathrm{~N} \mathrm{~m}$. For comparison, the simulated current with constant inductance (averaged value) is also given. It can be found that both the magnitude and waveform of the phase current are affected by the inductance variation, and the effect can also be observed in the electromagnetic torque, as shown in Fig. 3.

Experiments have been carried out for both the steady state and dynamic performances. ${ }^{5}$ As an example, Fig. 4 shows the measured phase current. The line voltage of the

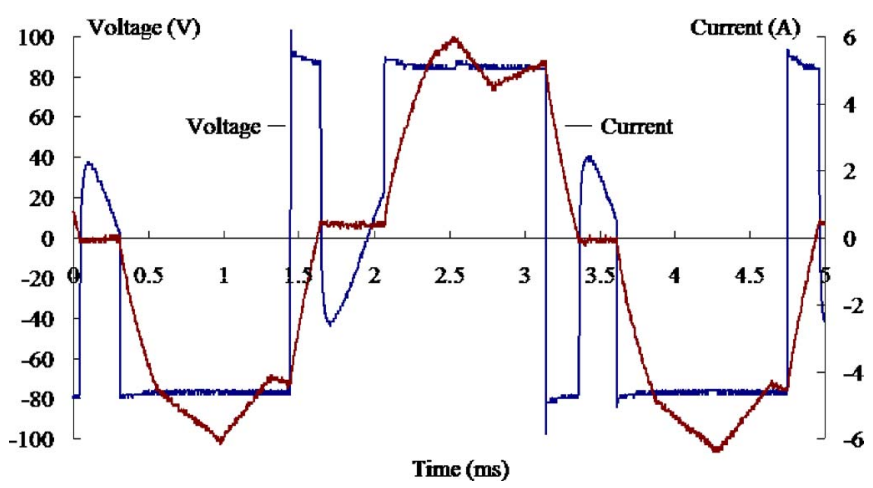

FIG. 4. (Color online) Measured phase current with a load of $2.65 \mathrm{~N} \mathrm{~m}$ at $1800 \mathrm{rpm}$

same phase with respect to the negative dc link terminal is also plotted. The simulated current agrees generally with the measurement.

\section{CONCLUSION}

This paper presents the influence of inductance variation on the performance of a permanent magnet claw pole motor by using a Simulink-based improved phase variable model. Simulation results show that the phase current and the electromagnetic torque are significantly affected by the variation of winding inductance. It is therefore important to include the effect of inductance variation in advanced design and analysis of electrical machines, particularly those with large inductance values and variations. Both the inductance computation and motor performance prediction are verified by the experimental results on the motor prototype.

\footnotetext{
${ }^{1}$ Höganäs AB, reports 1997-2007 (http://www.hoganas.com/).

${ }^{2}$ A. G. Jack, Proceedings of the International Conference on Electrical Machines, Istanbul, Turkey, September 1998, p. 1441.

${ }^{3}$ Y. G. Guo, J. G. Zhu, P. A. Watterson, and W. Wu, IEEE Trans. Ind. Appl. 39, 1696 (2003).

${ }^{4}$ Y. G. Guo, J. G. Zhu, P. A. Watterson, W. M. Holliday, and W. Wu, IEEE International Conference on Power Electronics and Drive Systems, Singapore, November 2003, p. 704.

${ }^{5}$ Y. G. Guo, J. G. Zhu, P. A. Watterson, and W. Wu, J. Electr. Electron. Eng., Aust. 2, 21 (2005).

${ }^{6}$ Y. G. Guo, J. G. Zhu, and H. Y. Lu, IEE Proc.: Electr. Power Appl. 153, 568 (2006).

${ }^{7}$ Y. G. Guo, J. G. Zhu, and H. Y. Lu, IEEE Trans. Magn. 43, 1072 (2007).

${ }^{8}$ Y. P. Dou, Y. G. Guo, J. G. Zhu, and H. Y. Lu, IEEE Trans. Magn. 43, 2561 (2007).

${ }^{9}$ O. A. Mohammed, S. Liu, and Z. Liu, IEEE Trans. Magn. 41, 1576 (2005).

${ }^{10}$ J. X. Chen, Y. G. Guo, J. G. Zhu, and J. X. Jin, Proceedings of the IEEE IAS Annual Meeting, New Orleans, USA, September 2007, p. 2169.
} 